\section{Kidney \\ Blood Pressure Research}

\title{
Elevated Asymmetric Dimethylarginine is Associated With Oxidant Stress Aggravation in Patients With Early Stage Autosomal Dominant Polycystic Kidney Disease
}

\author{
Vassilios Raptis ${ }^{a}$ Panagiotis I. Georgianos ${ }^{a}$ Pantelis A. Sarafidis ${ }^{a}$ \\ Athanasios Sioulis $^{\mathrm{a}} \quad$ Kali Makedou $^{\mathrm{b}} \quad$ Areti Makedou $^{\mathrm{c}}$ Dimitrios M. Grekas ${ }^{\mathrm{d}}$ \\ Stergios Kapoulas ${ }^{a}$ \\ aSection of Nephrology and Hypertension, 1st Department of Medicine, AHEPA University Hospital; \\ 'Laboratory of Biological Chemistry, Faculty of Medicine, Aristotle University of Thessaloniki; \\ cLaboratory for Lipids and Cardiovascular Disease Prevention, 2nd Pediatric Department; ${ }^{\mathrm{d}} 1 \mathrm{st}$ \\ Propedeutic Department of Internal Medicine, AHEPA University Hospital, Thessaloniki, Greece
}

\section{Key Words}

Asymmetric dimethylarginine $\cdot$ ADMA - autosomal dominated polycystic kidney disease $•$ $\mathrm{ADPKD} \cdot \mathrm{eGFR} \cdot$ Oxidative stress

\begin{abstract}
Background/Aims: In experimental models of polycystic kidney disease impaired bioavailability of nitric oxide (NO) and elevated mRNA expression of oxidative stress markers at the kidney level was noted. However, clinical studies investigating the potential role of endothelial dysfunction and oxidative stress in the pathogenesis of autosomal dominant polycystic kidney disease (ADPKD) are limited. We evaluated asymmetric dimethylarginine (ADMA) as marker of $\mathrm{NO}$ synthase inhibitor as well as $15-\mathrm{F}_{2 \mathrm{t}}$-Isoprostane and oxidized-low density lipoprotein (oxidized-LDL) as measures of oxidative stress in patients with early stages ADPKD. Methods: We recruited 26 ADPKD patients (Group A) with modestly impaired renal function (eGFR 45-70 $\mathrm{ml} / \mathrm{min} / 1.73 \mathrm{~m}^{2}$ ), 26 age- and sex-matched ADPKD patients (Group B) with relatively preserved renal function (eGFR) $>70 \mathrm{ml} / \mathrm{min} / 1.73 \mathrm{~m}^{2}$ ), and 26 age- and sex-matched controls (Group C). Determination of circulating levels of ADMA, 15- $\mathrm{F}_{2 \mathrm{t}}$-Isoprostane, oxidized-LDL and routine biochemistry was performed. Results: Group A and B had significantly higher ADMA levels as compared to controls $(1.68 \pm 0.7$ vs $0.51 \pm 0.2 \mu \mathrm{mol} / \mathrm{l}, \mathrm{P}<0.001$ and $1.26 \pm 0.7 \mathrm{vs} 0.51 \pm 0.2 \mu \mathrm{mol} / \mathrm{l}$, $\mathrm{P}<0.001$, respectively). $15-\mathrm{F}_{2 \mathrm{t}}$-IsoP and oxidized-LDL levels were also significantly higher in Group B relative to controls $(788.8 \pm 185.0$ vs $383.1 \pm 86.0 \mathrm{pgr} / \mathrm{ml}, \mathrm{P}<0.001$ and $11.4 \pm 6.6$ vs
\end{abstract}




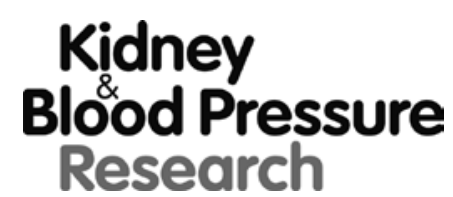

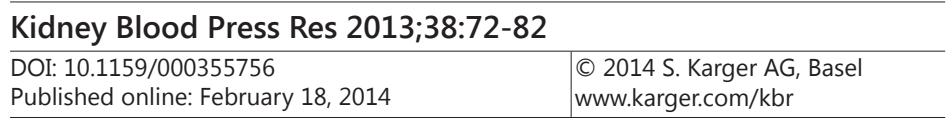

Raptis et al.: ADMA and Oxidant Stress Aggravation in ADPKD

$6.4 \pm 2.6 \mathrm{EU} / \mathrm{ml}, \mathrm{P}<0.05$ respectively) and were further elevated in Group A. In correlation analysis, ADMA levels exhibited strong associations with levels of $15-F_{2 t}$-Isoprostane $(r=0.811$, $P<0.001)$ and oxidized-LDL $(r=0.788, P<0.001)$, whereas an inverse correlation was evident between ADMA and eGFR ( $r=-0.460, P<0.001)$. Conclusion: This study shows elevation in circulating levels of ADMA along with aggravation of oxidative stress from the early stages of ADPKD.

Copyright $\odot 2014$ S. Karger AG, Basel

\section{Introduction}

Autosomal dominant polycystic kidney disease (ADPKD) is the most commonly occurring hereditary disorder causing chronic kidney disease (CKD) worldwide, whereas about $5 \%$ of patients reaching end-stage renal disease (ESRD) in both sites of the Atlantic have ADPKD as the primary cause of renal failure [1]. The natural course of ADPKD is rather distinct from other primary kidney diseases, as in the majority of patients renal function is maintained within the normal range until fourth to sixth decade of life, whereas hypertension is an early event and usually occurs prior to renal function deterioration[1]. Apart from the well-established role of kidney enlargement and renal cysts growth [2, 3], several aspects regarding pathogenesis and progression of kidney injury in ADPKD remain unclear.

Background studies have shown decreased production and bioavailability of nitric oxide (NO) at the kidney level in experimental models of ADPKD [4, 5]. In addition, clinical studies have revealed that ADPKD patients with normal renal function have impaired endotheliumdependent vasodilatation in different vascular beds, suggesting that endothelial dysfunction may represent a special feature in these patients $[6,7]$. Asymmetric dimethylarginine (ADMA) is a naturally occurring amino-acid acting as inhibitor of NO synthase and is considered a risk factor for endothelial dysfunction and cardiovascular disease [8, 9]. Several lines of evidence have suggested that ADMA may also represent a marker of CKD progression [8, 9]. In this context, it was hypothesized that inhibition of NO synthase activity by ADMA may represent one potential mechanistic pathway for endothelial dysfunction and kidney injury progression in ADPKD. However, clinical studies evaluating levels of ADMA in these patients are very few $[10,11]$ and suffer from limitations.

In addition to the above, experimental and clinical studies have shown that aggravation of oxidative stress can promote kidney injury through a number of mechanisms, including interference with bioavailability of NO at the kidney level $[12,13]$. Animal studies have also suggested that impaired oxidant-antioxidant balance exacerbates renal function decline in experimental models of rapidly progressive polycystic kidney disease $[14,15]$. However, the question whether increase in oxidative stress occurs from the early stages of ADPKD and to what extent reduced anti-oxidant protection is implicated in pathophysiology of endothelial dysfunction and renal damage in these patients remain unknown, as clinical studies evaluating oxidant status and its association with the NO pathway in ADPKD are limited $[11,16]$.

In this context, the aim of the present study is to investigate the levels of ADMA in relation to $15-\mathrm{F}_{2 \mathrm{t}}$-Isoprostane (15- $\mathrm{F}_{2 \mathrm{t}}$-Isop) and oxidized-low density lipoprotein (oxidizedLDL), which are proposed to be two highly accurate circulating measures of oxidative stress in vivo [17], in ADPKD patients with modestly impaired and preserved renal function.

\section{Material and Methods}

\section{Study population}

All consecutive ADPKD patients attending the Nephrology Outpatient Clinic of AHEPA University Hospital, Thessaloniki Greece, and General Hospital of Pieria, Katerini, Greece during the calendar years 2010 and 2011 were evaluated for possible recruitment in this study. Initial evaluation included detailed 


\section{Kidney \\ Blood Pressure Research}

Kidney Blood Press Res 2013;38:72-82

\begin{tabular}{l|l}
\hline DOI: $10.1159 / 000355756$ & (C) 2014 S. Karger AG, Basel
\end{tabular}

Published onlıne: February 18, 2014

www.karger.com/kbr

Raptis et al.: ADMA and Oxidant Stress Aggravation in ADPKD

medical history, physical examination and standard laboratory tests. Inclusion criteria consisted of: a) patient to have a documented diagnosis of ADPKD, according to standard ultrasonographic criteria and positive family history of the disease; b) age from 18 to 65 years; c) patient to have provided informed written consent. Patients were excluded from the study in case of: a) CKD stage IIIb or higher, with an estimated glomerular filtration rate (eGFR) below of $45 \mathrm{ml} / \mathrm{min} / 1.73 \mathrm{~m}^{2}$, defined according to the National Kidney Foundation-Kidney Disease Outcomes Quality Initiative (NKF-KDOQI) guidelines [18]; b) acute or chronic inflammatory disease; c) current use of cyclooxygenase inhibitors or vitamin E supplements; d) history of complicated renal cysts in the 3 previous months prior to study enrollment; e) acute myocardial infarction, unstable angina or ischemic stroke during the past 3 months; f) evidence of peripheral occlusive arterial disease; g) stage III-IV heart failure, according to the New York Heart Association (NYHA) criteria.

A total of 52 ADPKD patients fulfilling the above inclusion/exclusion criteria who volunteered to undertake the protocol procedures were finally enrolled in this study. The patient population consisted of 2 groups: the first (Group A) included 26 ADPKD patients with modestly impaired renal function i.e., eGFR ranging from 45 to $70 \mathrm{ml} / \mathrm{min} / 1.73 \mathrm{~m}^{2}$ and the second group (Group B) included 26 age- and sex-matched ADPKD patients with relatively preserved renal function i.e., eGFR $>70 \mathrm{ml} / \mathrm{min} / 1.73 \mathrm{~m}^{2}$. Another 26 age- and sex-matched volunteers (either healthy or with mild primary hypertension and serum creatinine within normal levels) formed the control group of this study (Group C). All protocol procedures were conducted in accordance with the Declaration of Helsinki (2000 amendment) and study protocol was approved by the Ethics Committee of School of Medicine, Aristotle University of Thessaloniki. All study participants provided informed written consent prior to study initiation.

\section{Study protocol}

Study participants came to the Nephrology Outpatient Clinic of our department after a 12-hour overnight fast and without having received their morning medication. For the purposes of the study, information regarding demographic characteristics, medical history and concomitant medication, smoking habits as well as anthropometric and office blood pressure (BP) measurements were recorded in a standardized manner for each individual patient. On the previous day, study participants have performed a 24-hour urinary collection to determine the urinary albumin and creatinine excretion. Finally, all study participants gave blood samples in the morning in order to determine standard hematological and biochemical parameters as well as markers of endothelial dysfunction and oxidative stress under study. Estimation of GFR was performed with the use of the Modification of Diet in Renal Disease (MDRD) study formula, according to the guidelines [18].

\section{Laboratory Analyses}

Routine hematological and biochemical parameters were measured with standard laboratory methods. For the determination of markers of endothelial dysfunction and oxidative blood samples were collected in standard EDTA tubes and were immediately centrifuged. The supernatants were stored at $-70^{\circ} \mathrm{C}$ until the quantitative determination of the parameters under study. Levels of ADMA were measured with the method of competitive enzyme-linked immunoassay using a commercially available ELISA kit (Immunodiagnostik AG, Bensheim, Germany). The method has a high sensitivity and specificity and intra- and inter-assay coefficients of variation of well below $5 \%$, respectively [19]. Plasma $15-\mathrm{F}_{2 \mathrm{t}}$-IsoP levels were determined with an enzyme immunoassay using a standard commercial kit (Cayman Chemicals, Ann Arbor, Mich., USA). Oxidized-LDL levels were assessed by a competitive ELISA utilizing a specific murine monoclonal antibody (Mercodia Oxidized LDL ELISA, Uppsala, Sweden). High sensitivity C reactive protein (hsCRP) was quantified with an immunonephelometric method (CardioPhase hsCRP, Dade Behring, USA) in Nephelometer BN 100 (Dade Behring, Germany). Homocysteine was determined by fluorescence polarization immunoassay, using Abbot IMx analyzer (Abbot Diagnostics, Abbot Park, Ill).

\section{Statistical analysis}

Statistical analysis was performed using the Statistical Package for Social Sciences (SPSS) software version 17 (SPSS Inc, Chicago, Ill, USA) for Windows XP. Continuous variables are expressed as mean \pm standard deviation (mean $\pm \mathrm{SD}$ ). Between groups comparisons for categorical variables were performed with the Chi Square $\left(\chi^{2}\right)$ test or Fisher's exact test and for continuous variables with one-way analysis of variance (ANOVA). To explore the differences between various pairs of the three study groups, we 


\section{Kidney \\ Blood Pressure Research}

\begin{tabular}{|c|c|}
\hline Kidney Blood Press Res 201 & \\
\hline $\begin{array}{l}\text { DOI: } 10.1159 / 000355756 \\
\text { Published onlıne: February 18, } 2014\end{array}$ & $\begin{array}{l}\text { (c) } 2014 \text { S. Karger AG, Basel } \\
\text { www.karger.com/kbr }\end{array}$ \\
\hline
\end{tabular}

Table 1. Comparison of patient characteristics between study groups

\begin{tabular}{|c|c|c|c|c|}
\hline Parameter & $\begin{array}{l}\text { ADPKD with } \\
\text { impaired renal } \\
\text { function }\end{array}$ & $\begin{array}{l}\text { ADPKD with } \\
\text { preserved renal } \\
\text { function }\end{array}$ & Controls & P-Value \\
\hline $\mathrm{N}$ & 26 & 26 & 26 & \\
\hline Age (years) & $44.0 \pm 12.1$ & $43.0 \pm 11.2$ & $43.5 \pm 14.1$ & $>0.90$ \\
\hline $\operatorname{Sex}(M / F)$ & $13 / 13$ & $13 / 13$ & $13 / 13$ & $>0.90$ \\
\hline Weight & $73.0 \pm 13.7$ & $80.8 \pm 17.1$ & $69.5 \pm 12.0$ & $<0.05$ \\
\hline History of hypertension & $17 / 26$ & $20 / 26$ & $13 / 26$ & 0.154 \\
\hline Age onset of hypertension (years) & $32.9 \pm 11.3$ & $35.4 \pm 9.0$ & $41.9 \pm 13.8$ & 0.098 \\
\hline Presence of hematouria & $17 / 26$ & $18 / 26$ & $0 / 26$ & $<0.001$ \\
\hline Age onset of hematouria (years) & $31.2 \pm 9.9$ & $35.0 \pm 10.2$ & - & 0.270 \\
\hline Presence of albuminuria & $19 / 26$ & $8 / 26$ & $2 / 26$ & 0.087 \\
\hline Urinary albumin excretion (mg/day) & $340.5 \pm 56.6$ & $145 \pm 57.2$ & $15.4 \pm 11.0$ & $<0.001$ \\
\hline $\operatorname{eGFR}\left(\mathrm{ml} / \mathrm{min}^{*} 1.73 \mathrm{~m}^{2}\right)$ & $51.7 \pm 5.0$ & $89.5 \pm 13.1$ & $90.8 \pm 10.1$ & $<0.001$ \\
\hline Current smokers & $15 / 26$ & $13 / 26$ & $13 / 26$ & 0.814 \\
\hline SBP (mmHg) & $135.2 \pm 7.3$ & $132.0 \pm 7.1$ & $129.8 \pm 7.8$ & $<0.05$ \\
\hline DBP (mmHg) & $80.4 \pm 10.2$ & $83.3 \pm 5.4$ & $79.0 \pm 7.1$ & 0.145 \\
\hline Hematocrit (\%) & $40.3 \pm 3.0$ & $40.1 \pm 2.2$ & $38.4 \pm 2.0$ & $<0.05$ \\
\hline Hemoglobin (mg/dl) & $13.3 \pm 1.0$ & $13.2 \pm 0.7$ & $12.9 \pm 1.0$ & 0.388 \\
\hline Serum urea $(\mathrm{mg} / \mathrm{dl})$ & $68.9 \pm 21.9$ & $42.9 \pm 18.2$ & $32.7 \pm 8.7$ & $<0.001$ \\
\hline Serum creatinine $(\mathrm{mg} / \mathrm{dl})$ & $1.8 \pm 0.5$ & $1.1 \pm 0.4$ & $1.0 \pm 0.3$ & $<0.001$ \\
\hline Uric acid (mg/dl) & $6.7 \pm 0.8$ & $6.0 \pm 0.8$ & $5.8 \pm 0.5$ & $<0.001$ \\
\hline Total-Cholesterol (mg/dl) & $191.6 \pm 18.0$ & $181.8 \pm 17.4$ & $174.5 \pm 24.8$ & $<0.05$ \\
\hline LDL-Cholesterol (mg/dl) & $110.9 \pm 16.8$ & $99.9 \pm 18.2$ & $95.5 \pm 21.1$ & $<0.05$ \\
\hline HDL-Cholesterol (mg/dl) & $52.6 \pm 5.0$ & $54.6 \pm 4.5$ & $51.6 \pm 4.6$ & 0.075 \\
\hline Triglycerides (mg/dl) & $140.1 \pm 12.7$ & $136.7 \pm 14.4$ & $136.6 \pm 22.2$ & 0.714 \\
\hline History of urinary track infections & $12 / 26$ & $13 / 26$ & $9 / 26$ & 0.266 \\
\hline Number of antihypertensive agents & $2.7 \pm 1.7$ & $1.4 \pm 1.1$ & $0.6 \pm 0.2$ & $<0.001$ \\
\hline ACEi & $15 / 26$ & $10 / 26$ & $5 / 26$ & 0.157 \\
\hline ARBs & $13 / 26$ & $7 / 26$ & $4 / 26$ & 0.370 \\
\hline CCBs & $2 / 26$ & $0 / 26$ & $1 / 26$ & 0.474 \\
\hline b-blockers & $15 / 26$ & $11 / 26$ & $5 / 26$ & 0.091 \\
\hline Statins & $11 / 26$ & $6 / 26$ & $3 / 26$ & 0.344 \\
\hline
\end{tabular}

Abbreviations: $\mathrm{ADPKD}=$ autosomal dominant polycystic kidney disease; eGFR=estimated glomerular filtration rate; $\mathrm{SBP}=$ systolic blood pressure; $\mathrm{DBP}=$ diastolic blood pressure; LDL-Cholesterol= low density lipoprotein-Cholesterol; HDL-Cholesterol= high density lipoprotein-Cholesterol; ACEi= angiotensin converting enzyme inhibitors; $\mathrm{ARBs}=$ angiotensin receptor blockers; $\mathrm{CCBs}=$ calcium channel blockers. Data are presented as mean \pm SD

performed Student's t tests for independent variables with the Bonferroni correction for multiple testing. In addition, we performed simple linear regression analysis and calculated Pearson's $r$ correlation coefficients, to explore the possible relations between ADMA levels and the other parameters under study. A p value of $<0.05$ (two-tailed) was considered statistically significant.

\section{Results}

Baseline demographic, biochemical and treatment characteristics of study participants are presented in Table 1. ADPKD patients with impaired renal function had higher levels of serum urea and creatinine, greater urinary albumin excretion and lower eGFR as compared to both ADPKD patients with relatively preserved renal function and controls (Table 1). Patients with ADPKD and preserved renal function did not differ from controls in terms of SBP, DBP, serum urea and creatinine, eGFR, urinary albumin excretion, uric acid and serum lipid profile, but received higher number of antihypertensive agents and had more frequently positive history of hematuria than controls. Further, statistically significant differences 


\section{Kidney Blood Pressure Research}

Table 2. Comparisons of circulating markers of endothelial dysfunction and oxidative stress between study groups

\begin{tabular}{lcccc}
\hline Parameter & $\begin{array}{c}\text { ADPKD with } \\
\text { impaired renal } \\
\text { function }\end{array}$ & $\begin{array}{c}\text { ADPKD with } \\
\text { preserved } \\
\text { renal function }\end{array}$ & Controls & P-Value \\
\hline $\mathrm{N}$ & 26 & 26 & 26 & \\
ADMA $(\mu \mathrm{mol} / \mathrm{l})$ & $1.68 \pm 0.7$ & $1.26 \pm 0.7^{*}$ & $0.51 \pm 0.2$ & $<0.001$ \\
Isoprostan $(\mathrm{pgr} / \mathrm{ml})$ & $1383.8 \pm 629.3$ & $788.8 \pm 185.0^{*}$ & $383.1 \pm 86.0$ & $<0.001$ \\
Oxidized-LDL $(\mathrm{EU} / \mathrm{ml})$ & $20.1 \pm 10.9$ & $11.4 \pm 6.6^{*}$ & $6.4 \pm 2.6$ & $<0.001$ \\
Omocysteine $(\mu \mathrm{mol} / \mathrm{l})$ & $25.0 \pm 6.2$ & $22.6 \pm 16.8^{* *}$ & $12.5 \pm 3.0$ & $<0.001$ \\
hs-CRP $(\mathrm{mg} / \mathrm{dl})$ & $1.4 \pm 0.2$ & $0.7 \pm 0.2$ & $0.2 \pm 0.05$ & $<0.001$ \\
\hline
\end{tabular}

Abbreviations: $\mathrm{ADPKD}=$ autosomal dominated polycystic kidney disease; $\mathrm{ADMA}=$ asymmetric dymethylarginine; LDL= low density lipoprotein; hs-CRP= high sensitivity $C$ reactive protein;

${ }^{*} \mathrm{P}<0.001$ for the comparisons between ADPKD patients with preserved renal function and controls. ${ }^{* *} \mathrm{P}<0.05$ for the comparisons between ADPKD patients with preserved renal function and controls. Data are presented as mean \pm SD

Fig. 1. Comparisons of a) ADMA, b) $15-\mathrm{F}_{2 \mathrm{t}}$-isoprostane and c) oxidized-LDL levels between ADPKD patients with impaired renal function, ADPKD patients with preserved renal function, and controls.

were also evident in levels of total cholesterol, uric acid, SBP and number of antihypertensive agents between ADPKD patients with impaired renal function and controls (Table 1).

As shown in Table 2 and Figure 1, ADPKD patients with impaired renal function differed significantly from both groups of ADPKD patients with preserved renal function and controls with regards to ADMA, $15-\mathrm{F}_{2 \mathrm{t}}$-IsoP and oxidized-LDL $(\mathrm{P}<0.001$ for all comparisons). Patients with ADPKD and preserved renal function had higher circulating levels of ADMA than controls $(1.26 \pm 0.7$ vs $0.51 \pm 0.2 \mu \mathrm{mol} / \mathrm{l}$, $\mathrm{P}<0.001)$. Furthermore, statistically significant differences were observed in levels of $15-\mathrm{F}_{2 \mathrm{t}}$-IsoP and oxidized-LDL between ADPKD patients with normal renal function and controls $(788.8 \pm 185.0$ vs $383.1 \pm 86.0 \mathrm{pgr} / \mathrm{ml}, \quad \mathrm{P}<0.001$ and $11.4 \pm 6.6$ vs $6.4 \pm 2.6 \mathrm{EU} / \mathrm{ml}, \quad \mathrm{P}<0.05$, respectively).

ADPKD patients with preserved renal function had also higher homocysteine levels than controls, but these groups did not differ in terms of hsCRP. With regards to the group of ADPKD with impaired renal function, these patients

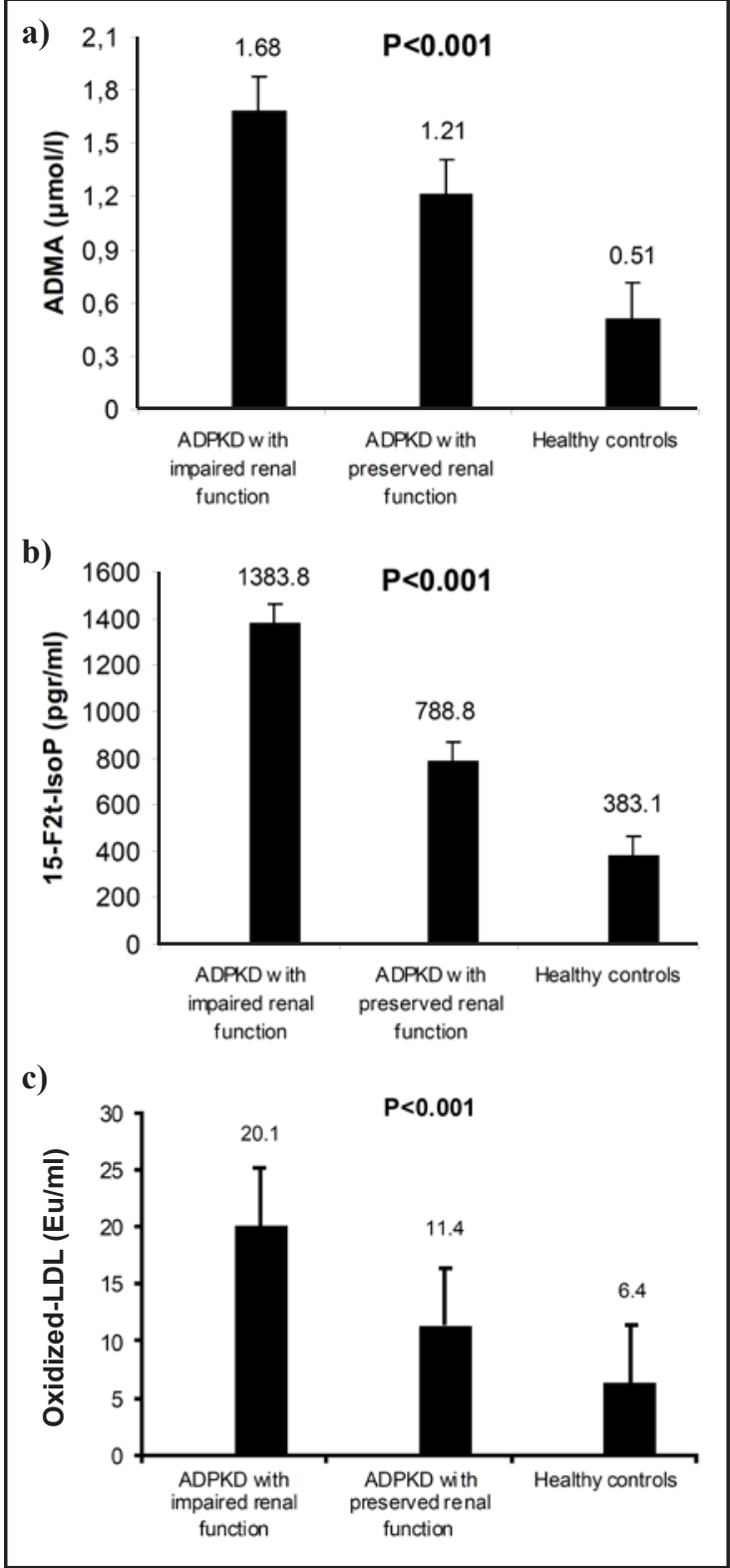




\section{Kidney \\ Blood Pressure Research}

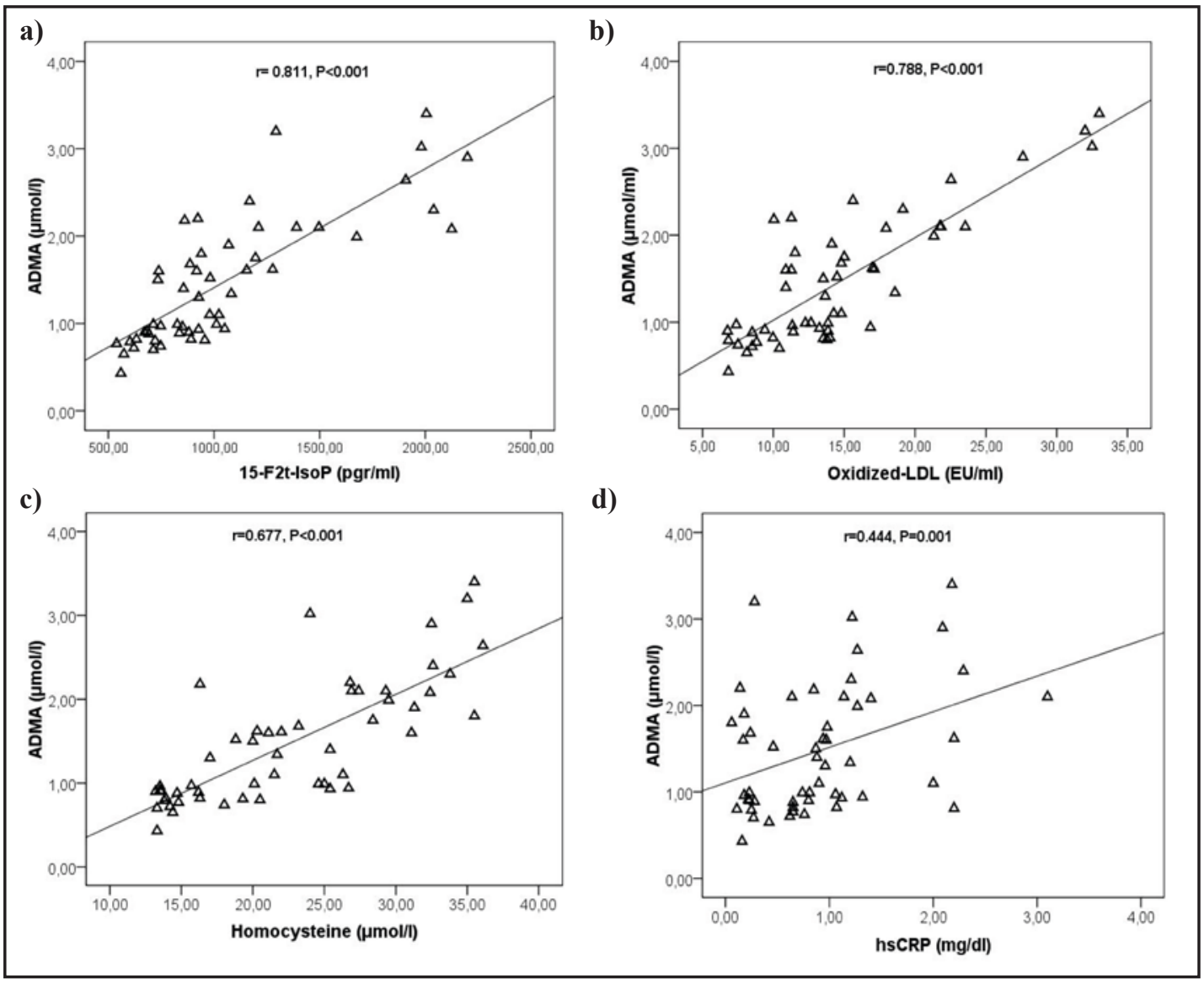

Fig. 2. Correlation analysis between circulating levels of $A D M A)$ and a) $15-\mathrm{F}_{2 \mathrm{t}}$-Isoprostane ( $\mathrm{r}=0.811$, $\mathrm{P}<0.001)$, b) oxidized-LDL $(\mathrm{r}=0.788, \mathrm{P}<0.001), \mathrm{c})$ homocysteine $(\mathrm{r}=0.677, \mathrm{P}<0.001)$ and $\mathrm{d}) \mathrm{hsCRP}(\mathrm{r}=0.444$, $\mathrm{P}=0.001$ ) in ADPKD patients.

had significantly higher levels of both homocysteine and hsCRP than controls, whereas no statistically significant differences in these parameters were observed between groups of ADPKD patients with impaired and preserved renal function (Table 2).

In an attempt to identify possible determinants of elevated levels of ADMA in patients with ADPKD we performed relevant correlation analyses. ADMA levels were not significantly related to urinary albumin excretion $(r=0.107, P=0.452)$, presence of hypertension $(r=0.207$, $\mathrm{P}=0.141)$ and smoking status $(\mathrm{r}=0.067, \mathrm{P}=0.636)$. As shown in Figure 2, ADMA levels exhibited strong positive associations with $15-\mathrm{F}_{2 \mathrm{t}}$-IsoP $(\mathrm{r}=0.811, \mathrm{P}<0.001)$, oxidized-LDL $(\mathrm{r}=0.788, \mathrm{P}<0.001)$, homocysteine $(\mathrm{r}=0.677, \mathrm{P}<0.001)$ and hsCRP levels $(\mathrm{r}=0.444, \mathrm{P}<0.001)$. In addition, correlation analysis revealed inverse associations of eGFR with levels of ADMA $(\mathrm{r}=-0.460, \mathrm{P}<0.001), 15-\mathrm{F}_{2 \mathrm{t}}$-IsoP $(\mathrm{r}=-0.578, \mathrm{P}<0.001)$ and oxidized-LDL $(\mathrm{r}=-0.513, \mathrm{P}<0.001)$, (Figure 3).

\section{Discussion}

This study sought to investigate levels of ADMA in relation to circulating markers of oxidative stress in early stage ADPKD. The main finding of this study was that ADMA levels were elevated in ADPKD patients with relatively preserved renal function as compared to age- and sex-matched controls, suggesting that NO synthase inhibition by ADMA may be 


\section{Kidney \\ Blood Pressure Research}

involved in the endothelial dysfunction detected in these patients from early stages. This increase in ADMA levels was shown to be associated with aggravation of oxidative stress, as levels of both $15-\mathrm{F}_{2 \mathrm{t}}$ IsoP and oxidized-LDL were also higher in ADPKD patients than controls with similar eGFR. ADMA, as well as indices of oxidative stress, were found to be further elevated in ADPKD patients with modestly impaired renal function, whereas significant associations of circulating ADMA, $15-\mathrm{F}_{2 \mathrm{t}}{ }^{-}$ IsoP, and oxidized-LDL with eGFR decline were evident.

Background and clinical studies have suggested that endothelial dysfunction may represent a special characteristic of vasculature in ADPKD patients from early stages of the disease. Wang et al. have shown impaired endothelium-dependent vasorelaxation in subcutaneous resistance vessels dissected from gluteal biopsy specimens from patients with ADPKD and normal eGFR [20, 21]. Subsequent studies revealed that flow-mediated dilatation of brachial artery assessed with the method of reactive hyperemia is reduced and pulse wave reflections from peripheral sites are amplified in ADPKD patients with preserved renal function $[6,7,22]$, suggesting a deficit in NO release in the small branches of the arterial tree. In this context, it was hypothesized that inhibition of NO synthase activity by ADMA may be implicated in the complex mechanistic background of endothelial dysfunction in these individuals

In addition, impaired NO metabolism due to elevation of ADMA was shown that occurs in non-ADPKD patients with other primary kidney diseases and normal renal function [23, 24]. Caglar et al showed that levels of ADMA and hs-CRP were significantly higher in 78 patients with non-diabetic proteinuric nephropathy and normal renal function as compared to 38 healthy controls, whereas ADMA levels exhibited significant association with urinary albumin excretion [23]. A subsequent study by Yilmaz et al.
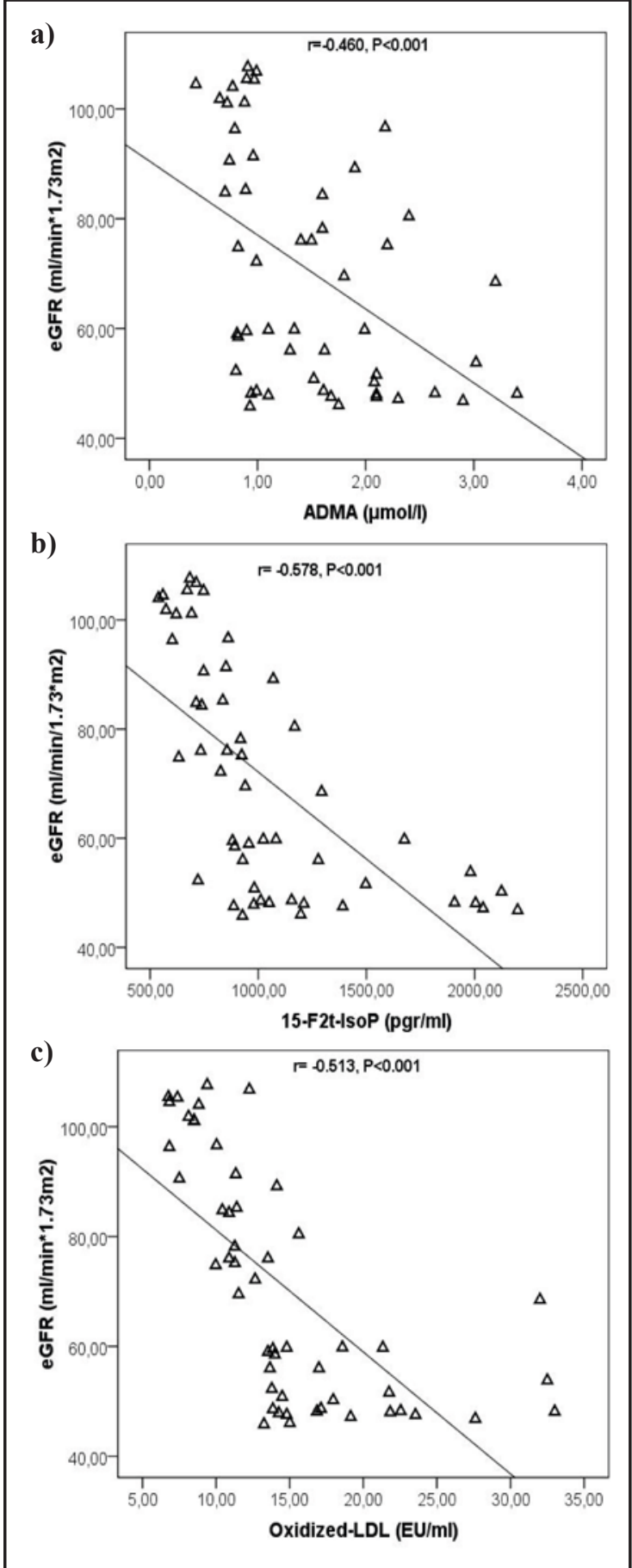

Fig. 3. Correlation analysis between estimated GFR and circulating levels of a) ADMA ( $\mathrm{r}=-0.460, \mathrm{P}<0.001)$, b) $15-\mathrm{F}_{2 \mathrm{t}}$-Isorostane $(\mathrm{r}=-0.578, \mathrm{P}<0.001)$ and $\left.\mathrm{c}\right)$ oxidized-LDL $(r=-0.513, \mathrm{P}<0.001)$ in patients with ADPKD .

proteinuric patients with preserved renal function (including also 39 patients with nephritic range proteinuria and secondary amyloidosis) had higher levels of ADMA and lower flowmediated vasodilatation of brachial artery in comparison with 50 age-, sex- and BMI-matched 


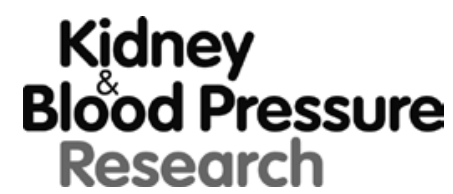

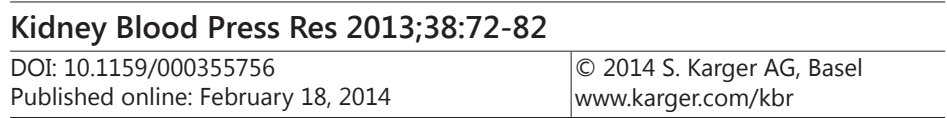

healthy individuals; again, proteinuria was significantly associated with levels of ADMA and measures of endothelial dysfunction [24].

Previous studies evaluating the potential role of ADMA in pathogenesis and progression of ADPKD are very few in number $[10,11]$ and have important methodological limitations such as small sample sizes, and lack of appropriate matching. In the first study of the field, Kielstein et al. [10] showed that 20 ADPKD patients with different stages of CKD have elevated levels of ADMA as compared to 16 normotensive, non-diabetic, non-smoking controls with normal renal function. When ADPKD population was stratified into different sub-groups according to the serum creatinine concentration, it was shown that elevation in ADMA levels occurred even in ADPKD patients with preserved renal function, but ADMA levels were not further elevated in the sub-groups of patients with advanced CKD; this could be attributed to the small sample-size of the study and to the even lower sample-size of the sub-groups (i.e. 6-8 patients) [10]. In a subsequent study, Wang et al. [11] observed that circulating levels of ADMA were significantly higher in a group of 27 ADPKD patients with normal renal function than in 30 age-matched healthy controls. This increase in ADMA was accompanied by elevated levels of 13-hydroxyoctadecadienoic acid (HODE), a lipid peroxidation product assessed as marker of oxidative stress [11]. However, this study did not include ADPKD patients with impaired renal function and failed to demonstrate a link between ADMA accumulation and oxidative stress aggravation [11]. The present study expands the previous findings, showing that elevation of ADMA is evident in ADPKD patients prior to eGFR decline, but it is further amplified in patients with modestly impaired renal function.

In addition to the above, the present study showed for first time that levels of $15-\mathrm{F}_{2 \mathrm{t}}$-IsoP and oxidized-LDL are elevated in patients with early stage ADPKD as compared to age- and sex-matched individuals without ADPKD. Experimental studies have revealed up-regulated mRNA expression of heme oxygenase-1, an inducible marker of oxidative stress, and reduced mRNA expression of anti-oxidant enzymes at the kidney level, both of which were associated with the severity of kidney injury in mouse and rat models of rapidly progressive polycystic kidney disease $[14,15,25]$. Increased LDL per se can be a possible mechanistic pathway for the aggravated oxidative stress in ADPKD [26, 27]. Since LDL-cholesterol enters into the endothelium of vessel walls, its molecule suffers an oxidative attack by reactive oxygen species (ROS), leading to the generation of oxidized-LDL. Subsequently, oxidized-LDL can initiate a vicious circle, i.e. enhance subclinical vascular inflammatory processes, which in turn further aggravate the cascade of oxidative stress [26, 27]. Increase in oxidative stress in early stage ADPKD is also supported by a recent clinical study, in which patients with ADPKD and eGFR above $60 \mathrm{ml} / \mathrm{min} / 1.73 \mathrm{~m}^{2}$ with or without hypertension had higher levels of 8-epi-prostaglandin $\mathrm{F}_{2 \mathrm{a}}\left(8-\mathrm{epi}-\mathrm{PGF}_{2 \mathrm{a}}\right)$ and superoxide dismutase (SOD) as compared to healthy controls [16].

Moreover, correlation analyses in the present study revealed strong positive associations of both $15-\mathrm{F}_{2 \mathrm{t}}$-IsoP and oxidized-LDL with levels of ADMA, suggesting that oxidative stress may be involved in impaired NO availability and metabolism. In this regard, the main metabolic pathway of ADMA is citrulline and dimethylamine or monomethylamine, a reaction catalyzed by $\mathrm{N}^{\mathrm{G}}, \mathrm{N}^{\mathrm{G}}$-dimethylarginine dimethylaminohydrolase (DDAH) [8]. Reduced anti-oxidant protection of the cysteine residue in the reactive site of DDAH can result in decreased DDAH activity and elevated circulating levels of ADMA during oxidative stress $[28,29]$. The link between oxidative stress and endothelial dysfunction in ADPKD is also supported by a recent experimental study [30] in mice with polycystic kidney disease 2. In that work, the acetylcholine-stimulated endothelium-dependent vasodilatation in isolated arterioles was impaired and accompanied by elevated basal superoxide and sodium nitroprusside-stimulated peroxynitrite formation in isolated vascular smooth muscle cells (VSMC), whereas these defects were reversible after the administration of the peroxisome proliferator-activated receptor- $\gamma$ (PPAR- $\gamma$ ) agonist rosiglitazone [30].

The finding of the present study that ADMA, 15- $\mathrm{F}_{2 \mathrm{t}}$-IsoP and oxidized-LDL accumulate in ADPKD patients from the early stages of the disease course and even before renal function decline suggests that endothelial dysfunction and oxidative stress may be involved in 


\section{Kidney \\ Blood Pressure Research}

development and progression of kidney injury in these patients. This hypothesis is supported by experiments showing impaired NO-dependent vasodilatation in renal arterioles and reduced expression of NO synthase in macula densa cells in rodent models of polycystic kidney disease $[4,5]$.

Additional support is provided by other studies showing that ADMA administration in uninephrectomized mice induces elimination of peri-tubular capillaries, up-regulation of mRNA expression of collagen type 1 and elevation in renal concentrations of transforming growth factor (TGF)- $\beta 1$, resulting in tubulointerstisial fibrosis [31, 32]. Further interference of free radical species with production and availability of $\mathrm{NO}$ at the kidney level may represent another mechanistic pathway through with oxidative stress promotes kidney damage in ADPKD [13]. Importantly, prospective cohort studies evaluating hard renal endpoints have demonstrated that ADMA represents strong and independent predictor of the rate of renal function decline in diabetic and non-diabetic CKD $[33,34]$.

Although, to the best of our knowledge, this work is the largest study evaluating levels of ADMA in relation to markers of oxidative stress in patients with ADPKD, there are still some methodological limitations that have to be acknowledged. First, a proportion of study participants had hypertension, albuminuria and were smokers. Despite the fact that ADMA was not associated with BP levels, urinary albumin excretion and smoking status in correlation analysis, the possibility that these factors may have influenced levels of ADMA cannot be excluded. In addition, this study evaluated only levels of ADMA in plasma and not in the urine; thus, to what extent reduced urinary ADMA excretion was involved in accumulation of circulating levels of ADMA cannot be estimated. Finally, as patient evaluation was performed in a single occasion, any cause-and-effect associations between ADMA, oxidative stress and kidney injury cannot be established in this study.

\section{Conclusion}

In conclusion, the present study showed that ADPKD patients with relatively preserved renal function have higher levels of ADMA, oxidized-LDL and 15- $\mathrm{F}_{2 \mathrm{t}}$-IsoP than non-ADPKD controls; these markers of endothelial dysfunction and oxidative stress were further elevated in ADPKD patients with modestly impaired renal function and were shown to be associated with the eGFR decline. Future prospective cohort studies will be required in order to fully elucidate whether this early occurrence of endothelial dysfunction and oxidative stress mediates kidney damage progression in patients with ADPKD.

\section{Conflict of Interests}

There are no conflicts of interest to disclose.

\section{Acknowledgements}

Authors wish to state that this work was not supported by any source and represents an original effort of our part.

\section{References}

1 Torres VE, Harris PC: Autosomal dominant polycystic kidney disease: the last 3 years. Kidney Int 2009;76:149-168. 


\section{Kidney \\ Blood Pressure Research}

\begin{tabular}{|c|c|}
\hline Kidney Blood Press Res 201 & \\
\hline $\begin{array}{l}\text { DOI: } 10.1159 / 000355756 \\
\text { Published onlıne: February 18, } 2014\end{array}$ & $\begin{array}{l}\text { (c) } 2014 \text { S. Karger AG, Basel } \\
\text { www.karger.com/kbr }\end{array}$ \\
\hline
\end{tabular}

2 Grantham JJ, Chapman AB, Torres VE: Volume progression in autosomal dominant polycystic kidney disease: the major factor determining clinical outcomes. Clin J Am Soc Nephrol 2006;1:148-157.

- 3 Torres VE, King BF, Chapman AB, Brummer ME, Bae KT, Glockner JF, Arya K, Risk D, Felmlee JP, Grantham JJ, Guay-Woodford LM, Bennett WM, Klahr S, Meyers CM, Zhang X, Thompson PA, Miller JP: Magnetic resonance measurements of renal blood flow and disease progression in autosomal dominant polycystic kidney disease. Clin J Am Soc Nephrol 2007;2:112-120.

-4 Wang D, Iversen J, Strandgaard S: Contractility and endothelium-dependent relaxation of resistance vessels in polycystic kidney disease rats. J Vasc Res 1999;36:502-509.

-5 Wang D, Braendstrup O, Larsen S, Horn T, Strandgaard S: The expression and activity of renal nitric oxide synthase and circulating nitric oxide in polycystic kidney disease rats. APMIS 2004;112:358-368.

6 Borresen ML, Wang D, Strandgaard S: Pulse wave reflection is amplified in normotensive patients with autosomal-dominant polycystic kidney disease and normal renal function. Am J Nephrol 2007;27:240-246.

-7 Kocaman O, Oflaz H, Yekeler E, Dursun M, Erdogan D, Demirel S, Alisir S, Turgut F, Mercanoglu F, Ecder T: Endothelial dysfunction and increased carotid intima-media thickness in patients with autosomal dominant polycystic kidney disease. Am J Kidney Dis 2004;43:854-860.

-8 Raptis V, Kapoulas S, Grekas D: Role of asymmetrical dimethylarginine in the progression of renal disease. Nephrology (Carlton) 2013;18:11-21.

-9 Schwedhelm E, Boger RH: The role of asymmetric and symmetric dimethylarginines in renal disease. Nat Rev Nephrol 2011;7:275-285.

10 Kielstein JT, Böger RH, Bode-Böger SM, Frölich JC, Haller H, Ritz E, Fliser D: Marked increase of asymmetric dimethylarginine in patients with incipient primary chronic renal disease. J Am Soc Nephrol 2002;13:170176.

11 Wang D, Strandgaard S, Borresen ML, Luo Z, Connors SG, Yan Q, Wilcox CS: Asymmetric dimethylarginine and lipid peroxidation products in early autosomal dominant polycystic kidney disease. Am J Kidney Dis 2008;51:184-191.

-12 Karamouzis I, Sarafidis PA, Karamouzis M, Iliadis S, Haidich AB, Sioulis A, Triantos A, Vavatsi-Christaki N, Grekas DM: Increase in oxidative stress but not in antioxidant capacity with advancing stages of chronic kidney disease. Am J Nephrol 2008;28:397-404.

13 Wilcox CS: Oxidative stress and nitric oxide deficiency in the kidney: a critical link to hypertension? Am J Physiol Regul Integr Comp Physiol 2005;289:R913-R935.

14 Maser RL, Vassmer D, Magenheimer BS, Calvet JP: Oxidant stress and reduced antioxidant enzyme protection in polycystic kidney disease. J Am Soc Nephrol 2002;13:991-999.

15 Torres VE, Bengal RJ, Litwiller RD, Wilson DM: Aggravation of polycystic kidney disease in Han:SPRD rats by buthionine sulfoximine. J Am Soc Nephrol 1997;8:1283-1291.

16 Menon V, Rudym D, Chandra P, Miskulin D, Perrone R, Sarnak M: Inflammation, oxidative stress, and insulin resistance in polycystic kidney disease. Clin J Am Soc Nephrol 2011;6:7-13.

17 Milne GL, Morrow JD: Isoprostanes and related compounds: update 2006. Antiox Redox Signal 2006;8:1379-1384.

-18 K/DOQI clinical practice guidelines for chronic kidney disease: evaluation, classification, and stratification. Am J Kidney Dis 2002;39:S1-266.

19 Schwedhelm E: Quantification of ADMA: analytical approaches. Vasc Med 2005;10:S89-S95.

-20 Wang D, Iversen J, Strandgaard S: Endothelium-dependent relaxation of small resistance vessels is impaired in patients with autosomal dominant polycystic kidney disease. J Am Soc Nephrol 2000;11:13711376.

21 Wang D, Iversen J, Wilcox CS, Strandgaard S: Endothelial dysfunction and reduced nitric oxide in resistance arteries in autosomal-dominant polycystic kidney disease. Kidney Int 2003;64:1381-1388.

-22 Heffernan KS, Kuvin JT, Sarnak MJ, Perrone RD, Miskulin DC, Rudym D, Chandra P, Karas RH, Menon V: Peripheral augmentation index and vascular inflammation in autosomal dominant polycystic kidney disease. Nephrol Dial Transplant 2011;26:2515-2521.

23 Caglar K, Yilmaz MI, Sonmez A, Cakir E, Kaya A, Acikel C, Eyileten T, Yenicesu M, Oguz Y, Bilgi C, Oktenli C, Vural A, Zoccali C: ADMA, proteinuria, and insulin resistance in non-diabetic stage I chronic kidney disease. Kidney Int 2006;70:781-787. 


\section{Kidney \\ Blood Pressure Research}

Kidney Blood Press Res 2013;38:72-82

DOI: 10.1159/000355756

Publisned onlıne: February 18, 2014

C 2014 S. Karger AG, Base

www.karger.com/kbr

-24 Yilmaz MI, Sonmez A, Saglam M, Qureshi AR, Carrero JJ, Caglar K, Eyileten T, Cakir E, Oguz Y, Vural A, Yenicesu M, Lindholm B, Stenvinkel P, Axelsson J: ADMA levels correlate with proteinuria, secondary amyloidosis, and endothelial dysfunction. J Am Soc Nephrol 2008;19:388-395.

25 Iakoubova OA, Dushkin H, Beier DR: Genetic analysis of a quantitative trait in a mouse model of polycystic kidney disease. Am J Respir Crit Care Med 1997;156:S72-S77.

26 Mizuno Y, Jacob RF, Mason RP: Inflammation and the development of atherosclerosis. J Atheroscler Thromb 2011;18:351-358.

-27 Tziomalos K, Athyros VG, Karagiannis A, Mikhailidis DP: Lipid lowering agents and the endothelium: an update after 4 years. Curr Vasc Pharmacol 2012;10:33-41.

28 Leiper J, Murray-Rust J, McDonald N, Vallance P: S-nitrosylation of dimethylarginine dimethylaminohydrolase regulates enzyme activity: further interactions between nitric oxide synthase and dimethylarginine dimethylaminohydrolase. Proc Natl Acad Sci USA 2002;99:13527-13532.

29 Vallance P, Leiper J: Blocking NO synthesis: how, where and why? Nat Rev Drug Discov 2002;1:939-950.

-30 Brookes ZL, Ruff L, Upadhyay VS, Huang L, Prasad S, Solanky T, Nauli SM, Ong AC: Pkd2 mesenteric vessels exhibit a primary defect in endothelium-dependent vasodilatation restored by rosiglitazone. Am J Physiol Heart Circ Physiol 2013;304:H33-H41.

-31 Mihout F, Shweke N, Bigé N, Jouanneau C, Dussaule JC, Ronco P, Chatziantoniou C, Boffa JJ: Asymmetric dimethylarginine (ADMA) induces chronic kidney disease through a mechanism involving collagen and TGF-beta1 synthesis. J Pathol 2011;223:37-45.

-32 Ueda S, Yamagishi S, Matsumoto Y, Kaida Y, Fujimi-Hayashida A, Koike K, Tanaka H, Fukami K, Okuda S: Involvement of asymmetric dimethylarginine (ADMA) in glomerular capillary loss and sclerosis in a rat model of chronic kidney disease (CKD). Life Sci 2009;84:853-856.

-33 Fliser D, Kronenberg F, Kielstein JT, Morath C, Bode-Böger SM, Haller H, Ritz E: Asymmetric dimethylarginine and progression of chronic kidney disease: the mild to moderate kidney disease study. J Am Soc Nephrol 2005;16:2456-2461.

-34 Hanai K, Babazono T, Nyumura I, Toya K, Tanaka N, Tanaka M, Ishii A, Iwamoto Y: Asymmetric dimethylarginine is closely associated with the development and progression of nephropathy in patients with type 2 diabetes. Nephrol Dial Transplant 2009;24:1884-1888. 